\title{
Barrellite and Pillarrite: A Description and a Mode of Formation of a Novel Post-Sedimentary Twin Structures from As-Subbiyah, North of Kuwait Bay, Kuwait
}

\author{
Ali T. Al-Mishwat \\ Department of Earth and Environmental Sciences, Kuwait University, Safat, Kuwait \\ Email: lemonfather@yahoo.com
}

How to cite this paper: Al-Mishwat, A.T. (2021) Barrellite and Pillarrite: A Description and a Mode of Formation of a Novel Post-Sedimentary Twin Structures from As-Subbiyah, North of Kuwait Bay, Kuwait. International Journal of Geosciences, 12, 625-634.

https://doi.org/10.4236/ijg.2021.127035

Received: June 16, 2021

Accepted: July 19, 2021

Published: July 22, 2021

Copyright $\odot 2021$ by author(s) and Scientific Research Publishing Inc. This work is licensed under the Creative Commons Attribution International License (CC BY 4.0). http://creativecommons.org/licenses/by/4.0/

\begin{abstract}
I report on the occurrence of a pair of novel and related post-sedimentary structures that form in the Neogene cross-bedded red sandstones in the As-Subbiyah area, north of Kuwait Bay, Kuwait. I named them barrellite and pillarrite. Barrellite forms as vertical tubes of concentric sheaths of siltstone with partially hollow interior or intervening homogeneous and structure-less sandstone. It stands as barrels above the background sandstone. Pillarrite forms as discrete, vertical and solitary spines of homogeneous sandstone and siltstone, or inside barrellite masses from which successive siltstone sheaths were stripped. The structures range in diameter from one-centimeter poke marks to one-meter-wide barrels and hunks, and their vertical length exceeds two meters. Barrellite, pillarrite and their complex intergrowths develop near thin quartz veins and chaotic zones, and form with them complex geometrical relationships. The dual structures are genetically related and fall within the general class of tubular structures in sedimentary rocks. I consider them as a special type of sand injectites. The mode of formation of these structures is enigmatic. They develop in a geological setting that displays evidence of a widespread and vigorous oil field brine. I suggest a tentative scenario for their formation, involving flushing of the brine through hydraulic fracturing of the sedimentary succession above the Ebharah Oil Field reservoir in the As-Subbiyah area. The brine plucks mineral and rock fragments and mixes with them along its paths, producing a heterogeneous slurry. Ultimately, the slurry solidifies as barrellite and pillarrite, chaotic zones and quartz veins. The vertical nature of the structures, circular and internal concentric arrangements, as well as the homogenous lithology inside their masses mimic characteristics of flow and deposits in vertical and horizontal pipelines.
\end{abstract}




\section{Keywords}

Barrellite, Pillarrite, As-Subbiyah, Kuwait, Post-Sedimentary, Twin Structure

\section{Introduction}

This paper describes the discovery of a pair of novel post-sedimentary structures in the Neogene siliciclastic section in the As-Subbiyah along the north coast of Kuwait Bay, Kuwait. I have assigned them the names barrellite and pillarrite, because they resemble barrels and pillars, respectively. Throughout the paper, I abbreviate them to brl and plr Search of the literature did not retrieve descriptions of similar structures. Although the literature ([1] [2]) describes a few occurrences of tubular structures, none of them resembles the brl and plr twin structures described here. Furthermore, authoritative textbooks on sedimentary structures ([3] [4] [5] [6]) do not contain structures to which the brl-plr pair is compared. Thus, the novelty of these structures stems from their absence in the literature, and by inference, in nature. [7] described briefly the discovery of the brl-plr structures.

I present in this paper a descriptive account of the geometry and intricate relationships among brl and plr masses, and related chaotic zones and quartz veins. I also propose a possible mode for their formation.

\section{Location}

The coastal region along the As-Subbiyah coast north of Kuwait Bay forms a narrow strip of desert that is underlain by sedimentary rocks of Neogene age. The brl-plr twin occurs in the area in many forms and sizes, but their characteristics show best in the cross-bedded red sandstones approximately 3.5 kilometers southeast of the fork in the Shaikh Saad Al-Abdullah Al-Subah Highway. Desert tracks lead from the highway to the cliffs below. The map in Figure 1(A) shows the location of the brl and plr structures in the As-Subbiyah (AS). The
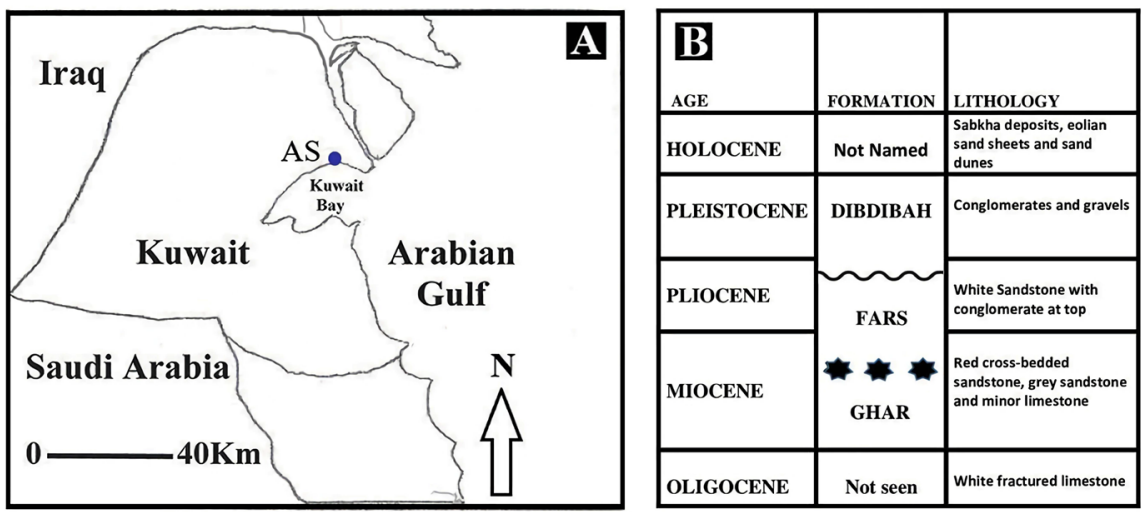

Figure 1. (A) A location map of the brl-plr outcrop in the As-Subbiyah area, Kuwait; (B) A local geologic column showing the stratigraphic position of the brl-plr structures (Stars). 
outcrop in this location displays the best development of the brl-plr dual and the intricate relationships between them and their host rocks.

\section{Local Stratigraphy}

The exposed sedimentary rock sequence hosting the brl-plr twin contains approximately 40 meters of Miocene-Pliocene sandstones and overlying limestone ([8] [9] [10]). The sandstone is a cross-bedded red sandstone, which frequently grades into yellow-tinted dolomite and sericite-rich pockets and lenses. Intercalated within the sequence are partings of thin brownish gray mudstone. The limestone is a well-laminated gray fossiliferous limestone. Figure $1(\mathrm{~B})$ shows the local succession and indicates the stratigraphic position of brl and plr structures within it.

\section{Descriptions of Barrellite and Pillarrite, and Related Features}

\subsection{Barrellite}

As the name suggests, the brl basic form is that of a concentric and vertical barrel-shaped tubes that cut their host rocks. These tubes form in a variety of shapes, but the geometrical element common to all of them is the hollow and circular interior (Figure 2(A)). Usually, the brl forms as a single and circular sheath of sandstone or siltstone that is partially internally hollow, and which is red to yellowish red in color. A brl also may be composed of several circular sheaths. Successive sheaths shield between them successive rings of eroded space, although much of this space contains plr or recent surficial accumulation of sand and debris. Several successive thin sheaths occur in some of the individual brl structures; as many as five thin sheaths line the interior of one brl whose diameter is one meter. Width of spaces between sheaths is not constant but varies from less than a centimeter to several centimeters. Sometimes sheaths cut cross each other in an anastomosing fashion, displaying a fascinating geometry.

Relationships between the brl and sheaths on one hand, and host sandstones on the other, are always truncating, cutting discordantly laminations and across bedding in the sandstone. Thin quartz vein swarms surround the best-preserved brl tubes. Angular fragments and inclusions of the host sandstone sometimes
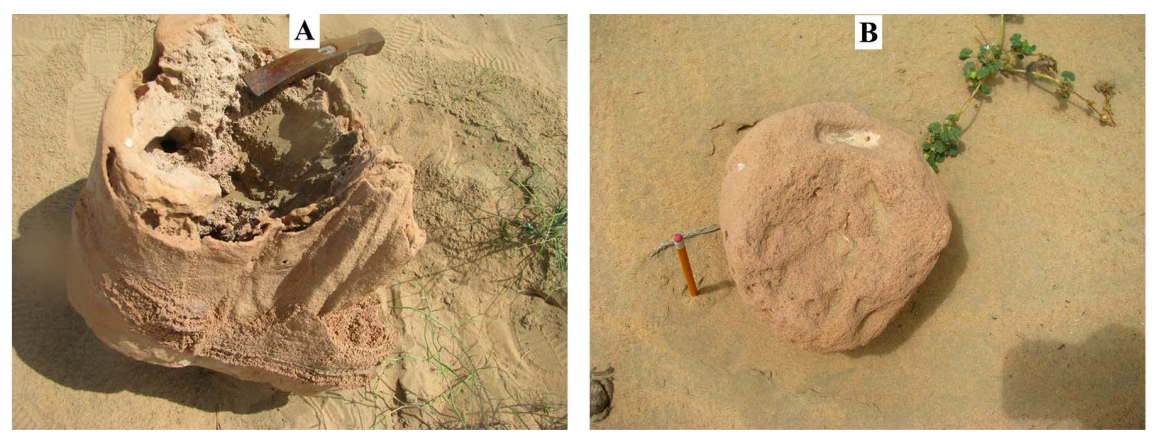

Figure 2. (A) A brl showing its general circular form, sheaths, and eroded hollow interior; (B) A plr showing its general circular spine and massive appearance. 
occur as rotated and inclined relative to their original geometry, reminiscent of rock inclusions in magmatic rocks. This is evident from tilting of layers and concave surfaces of cross beds.

\subsection{Pillarrite}

The fundamental shape of the plr is a spine of massive, structure-less and homogeneous siltstone (Figure 2(B)). The color of the spines is generally like that of the host red sandstone, but occasionally they are bleached and lighter in color.

Most spines are solitary. Their size varies from a few centimeters to eighty centimeters. Some of these plugs exhibit faint concentric zonation, involving variable grain size and shades of red and yellow colors. Smaller plr plugs, however, lack such variability.

The majority of the plr single occurrences is massive and completely circular spines of silhouette figures, projecting to more than half a meter above the background sandstone and recent cover of sand dunes and sheets. Below the outcrop surface, they pierce for three meters and traverse several sandstone layers, forming passages for transporting sand. Figure $3(\mathrm{~A})$ is such a passage. It displays a near-vertical plr conduit connecting to a horizontal layer-parallel sheet. Generally, the plr spines show a constant diameter along their length. Sometimes they are lobate, oval, or irregular in cross section; in extreme lobate cases, discoid spines measure forty centimeters in the long diameter.

Plr masses show extremely well cemented and invariably lack porosity, compared with the surrounding porous sandstones. Fresh pitting cavities occur along many plr spine surfaces, due to the removal of fine-grained cements because of weathering and wind abrasion. A crude correlation exists between grain size and porosity in the plr. Medium to fine-grained plr masses lack signs of porosity, but coarser-grained individuals contain slight porosity.
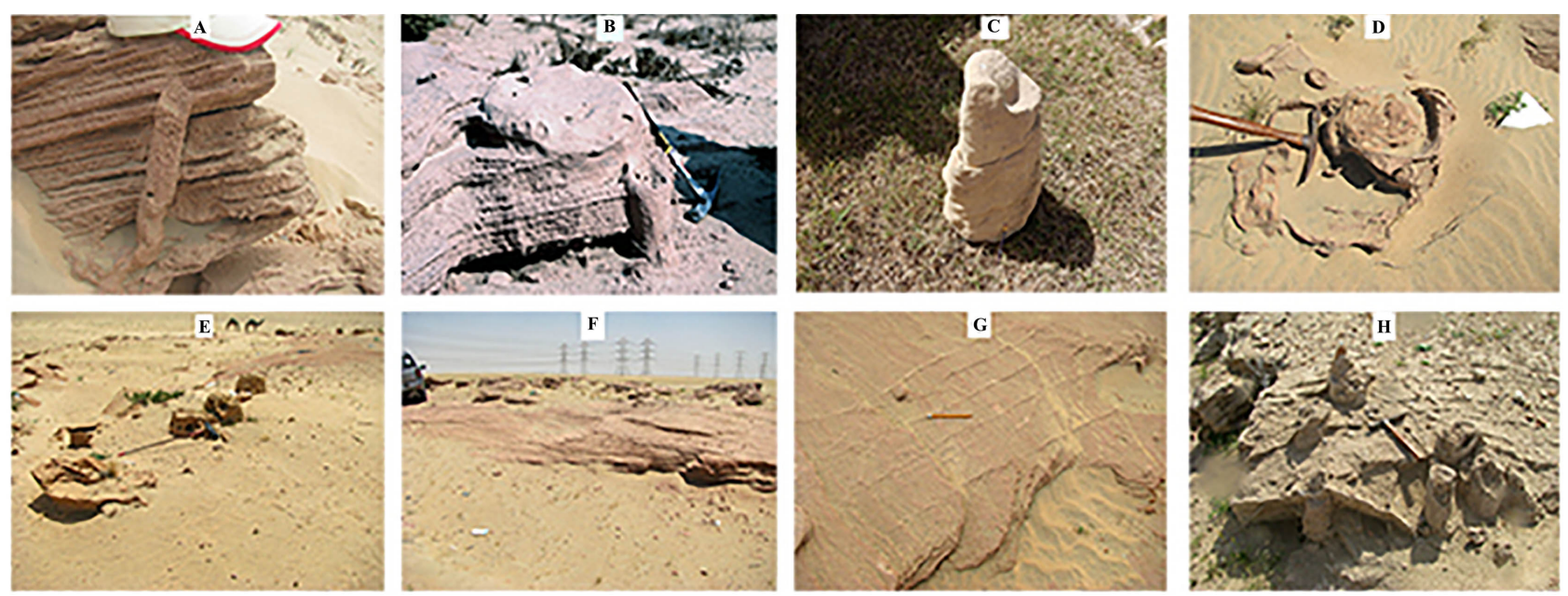

Figure 3. (A) A semi-vertical piercing sand mass discordant to layering; (B) A bedding-parallel zone of homogenized sand sheet connected to a vertical pillarrite; (C) Simplest of complexes; a plr inside a brl; (D) A complex showing intergrowth between two barrellites; (E) An array of brl-plr complexes; (F) A chaotic zone of irregular masses above a well-bedded red sandstone; (G) A swarm of quartz veins invading the red brl-plr outcrop; $(\mathrm{H})$ A swarm of quartz veins curving into a cluster of brl-plr. 
Though most plr spines are vertical, inclined structures also occur and pierce through the layered sandstone. In some cases, the plr changes to bedding-parallel masses. Wherever they occur in this configuration, they connect horizontally displaced vertical plr and brl structures (Figure 3(B)).

\subsection{Brl-plr Complexes}

By far, the most intriguing and intricate geometry shows in complexes of composite intergrowth of brl and plr. Figure 3(C) shows the simplest of complexes, a plr inside a brl. These complexes occur in various width, height and complexity. They reach one meter in diameter and height. Many of these complexes stand as solitary masses above the background sandstone. A typical intergrowth may contain several overlapping concentric brl sheaths, containing one or more piercing plr spines. As many as five brl and plr units show in some of the complexes. Figure 3(D) shows an intergrowth between two brls. Figure 3(E) displays an array of these complexes. Commonly, pillarrites do not occupy the middle of complexes, but are located closer towards complex peripheries.

A common feature associated with the brl-plr structures is chaotic zones oriented dominantly parallel to bedding. These zones are jumbled sandstone layers and masses (Figure 3(F)). They are structure-less and devoid of layering and laminations and other sedimentary features in rocks below and above these zones. The thickness of these zones is variable, reaching three meters in some places. These masses reach several hundred meters in length. These zones form part of the brl-plr networks.

\subsection{Quartz Veins}

The brl and plr bodies are closely associated with swarms of thin quartz veins (Figure $3(\mathrm{G})$ ). Veins are composed of fine to medium-grained yellowish white quartz. They are mostly vertical and linear, extending for several meters. Veins retain essentially same thicknesses along their length, being mostly less than half a centimeter. The veins occur in swarms and merge seamlessly into the brl and plr structures, where they become arcuate. Up to ten veins occur in a swarm. Swarms attain different directions in different parts of the outcrop. Frequently, quartz swarms curve into clusters of the brl-plr structures (Figure 3(H)).

A very complicated relationship exists between brl, plr, composite complexes and quartz vein swarms. Where near the brl and plr masses, veins assume perfectly concentric to irregularly curvilinear patterns. Away from the structures, these concentric vein swarms merge into the linear vein swarm sets and gradually lose their circular habit. As many as six concentric quartz veins intertwine within brl complexes. Where this relationship develops well, the curved veins extend outward for a distance comparable to the diameter of the structures and the complexes. Approximately one-meter zones rich in concentric and overlapping quartz veins envelope one-meter wide composite complexes.

Some of the concentric veins are inclined towards the brl-plr structures with a 
dip of about seventy degrees.

\section{Model}

Figure 4 is a block diagram showing schematically an idealized system of brl and plr structures, related chaotic zones and quartz veins. These structures are all produced by fluid expulsion [11]. The diagram illustrates the appearance of these features in map view and in the subsurface. It emphasizes the basic structures and remove the complexities clear in the field photographs (Figure 2, Figure 3). This diagram resembles the general opening banner of the sand injectites architecture in the comprehensive treatment of sand injectites by [12].

\section{Mode of Formation}

I discovered the brl-plr structures in 1997 and briefly reported on them [7]. The lack of a viable mechanism for their formation prevented a full report. Later, I discovered and mapped extensively a natural oil-field brine in the As-Subbiyah. The brine provides a plausible mode of formation. The suggested mechanism below is tentative and requires a future detailed research.

The Ebharah Oil Field Brine in As-Subbiyah is a widespread feature. It is a surface expression of a subsurface oil reservoir underlying the area. This brine is intermittently over-pressurized, resulting into periodic expulsions of hot brine fluids into the overlying sandstones. The brine scavenges thin fractures and induces hydraulic fracturing ([12] [13]). Initially, the brine focuses into existing thin cracks [14]. Along its path in fractures and joints, the brine incorporates rock fragments and plucks quartz grains and other rock components. During its ascent in passageways, the brine progressively evolves into a multi-phase slurry composed of a heterogeneous mixture of solids (rock and mineral fragments), liquid (fluidized brine) and gas (bubbles of hydrocarbon gases). Swirling and vortices-controlled turbid flow obliterates pre-existing sedimentary features, such as layering, cross bedding, and graded bedding. Ultimately, a heterogeneous slurry forms. The slurry is deposited as brl, plr, and chaotic zones. The main mechanism for propagating the slurry is flushing through vertical brl and plr and horizontal chaotic zones (Figure 3(B)) and connecting passageways, as contemplated in the model (Figure 4).

[15] discussed the relationships between quartz veins and hydrofracturing due to hydrothermal fluids. They believe episodic pressure buildup results into hydrofracturing and formation of quartz veins in fractures. This mechanism may be responsible for the formation of the swarms of quartz veins in the As-Subbiyah.

In the field of engineering, such a scenario is analogous to flow of heterogeneous multiphase slurries in vertical and horizontal pipelines (e.g. [16]-[23]). Voluminous literature is available on flow modes. Detailed mathematical formulation involving many variables like slurry composition, density, temperature, pressure, heat and mass transfer abound in the literature. 


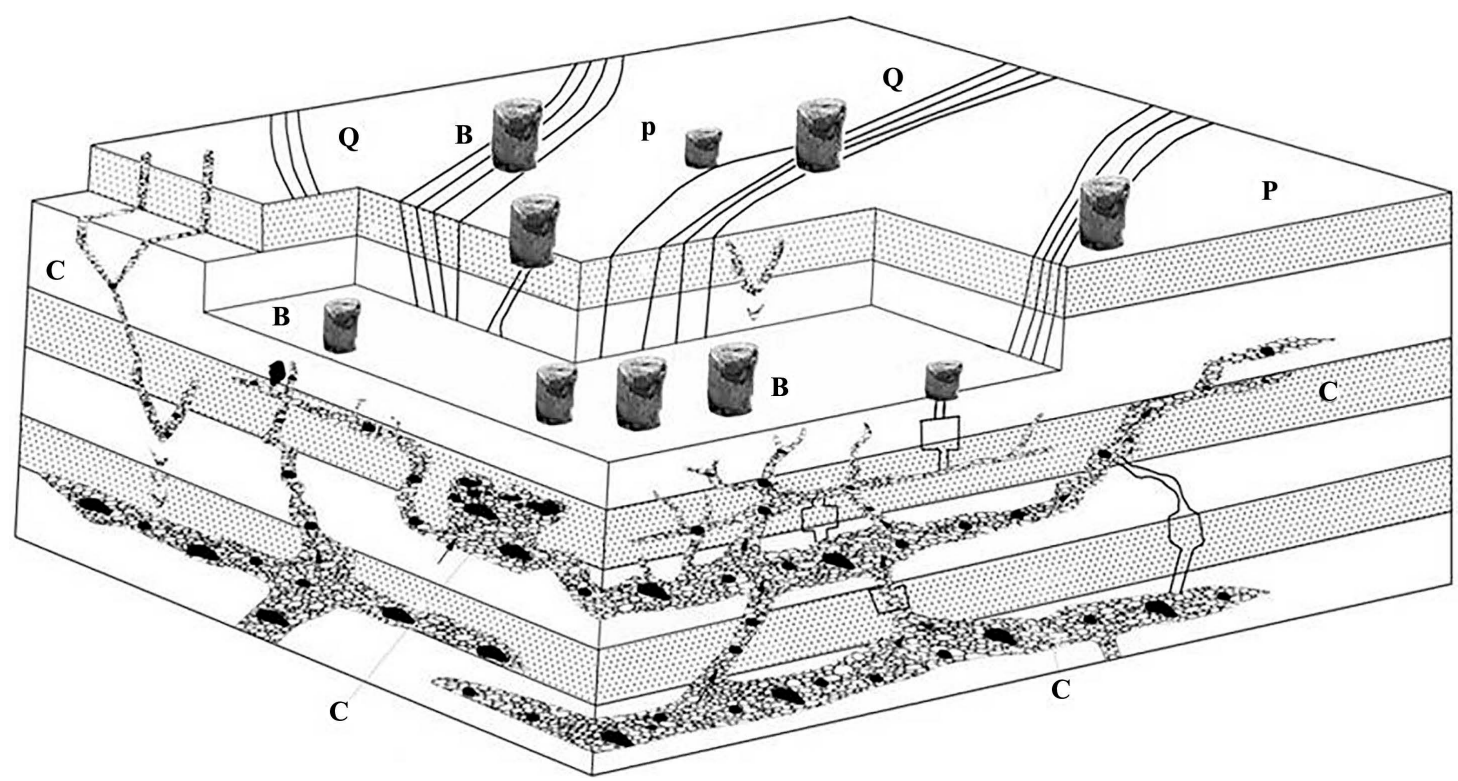

Figure 4. A model for the formation of the brl-plr structures and related features. A block diagram, modified after [12], showing the appearance of the brl, plr, chaotic zones, and quartz veins swarms, in map view and in the subsurface. (B for brl, $\mathrm{P}$ for plr, $\mathrm{C}$ for chaotic zone, and $\mathrm{Q}$ for quartz veins).

[24] discussed a model for slurry flow margins, utilizing mechanisms like mechanical sliding, viscous friction and off-wall particle lift, and also discussed a way to verify the near wall model of slurry flow. [25] described advances in studies of some aspects of turbulent multiphase flows. These mechanisms plausibly account for many of the features described in the brl-plr structures. Parallelism is drawn between the concentric internal arrangement of the brl and radial stratification inside vertical pipelines ([26] [27] [28]). In addition, slurry mixing and homogenization in the brl-plr networks may resemble accumulation of solid deposits in pipelines. Sand remobilization in brl-plr structures, chaotic zones, and passageways, perhaps form an analogue to sand remobilization described by [29], but on a much smaller scale. Considerable sand mobilization and redistribution results into the brl - plr networks.

[30] suggested an origin involving mud volcanoes and seismite in a sabkha setting for some members of these brl-plr masses and related structures. [31] suggested that large-scale pockmarks in the Niger Delta represent fluid expulsion from crestal areas of shallow-buried anticlinal reservoirs. [32] described similar structures to brl-plr twins from the Gale Crater on Mars. The brl and plr structures described in the present paper can potentially form a terrestrial analog to the Martian counterparts.

\section{Conclusions}

The brl and plr form two novel and related post-sedimentary structures in the Neogene red sandstones in the As-Subbiyah north of Kuwait Bay, Kuwait. The literature does not describe similar occurrences. The structures are complimentary to each other and to the quartz vein swarms and the associated chaotic 
zones. The brl forms as successive and vertical barrels containing concentric sheaths of sandstone in tube-in-tube arrangement and shows hollow interiors. Plr forms as homogeneous and structure-less vertical sandstone-siltstone spines. Both structures occur as simple solitary objects or as intricately complicated intergrowth complexes. The twin structures belong to the class of tubular structures described in authoritative references ([4] [6] [32]), but differ significantly from them geometrically. The structures form as small-scale sand injectites.

The dual brl-plr structures are the result of expulsion of an oil field brine in Ebharah in As-Subbiyah north of Kuwait Bay. The structures and their related features are potentially usable as proxy tools for expensive campaigns of hydrocarbon exploration in virginal target areas.

\section{Acknowledgements}

I thank the Car Transport Department in Kuwait University for provision of field vehicles. I thank Ahmad Abdi Hersi and Mohamad Nabawi for their assistance with images.

\section{Conflicts of Interest}

This research does not pose any conflict of interest.

\section{References}

[1] Cloud, P., Wright, L.A., Williams, E.G., Diehl, P. and Walter, M.R. (1974) Giant Stromatolites and Associated Vertical Tubes from the Upper Proterozoic Noonday Dolomite, Death Valley Region, Eastern California. Geological Society of America Bulletin, 85, 1869-1882. https://doi.org/10.1130/0016-7606(1974)85\%3C1869:GSAAVT\%3E2.0.CO;2

[2] Hegenberger, W. (1987) Gas Escape Structures in Precambrian Peritidal Carbonate Rocks. Communications of the Geological Survey South West Africa, Namibia, 3, 49-55.

[3] Collinson, J.D., Mountney, N. and Thompson, D.B. (2019) Sedimentary Structures, 4th Edition, Dunedin Academic Press, London, 204 p.

[4] Conybeare, C.E.B. and Crook, K.A.W. (1968) Manual of Sedimentary Structures. Bureau of Mineral Resources, Geology and Geophysics, Canberra, Bulletin No. 102, $327 \mathrm{p}$.

[5] Middleton, G.V. (1965) Primary Sedimentary Structures and Their Hydrodynamic Interpretation. Special Publication No. 12, Society of Economic Paleontologists and Mineralogists, Tulsa, $265 \mathrm{p}$.

[6] Pettijohn, F.J. and Potter, P.E. (1964) Atlas and Glossary of Primary Sedimentary Structures. Springer-Verlag, New York, 70. https://doi.org/10.1007/978-3-642-94899-2

[7] Al-Mishwat, A. (1998) Barrellite and Pillarrite: A Pair of Novel Rock Structures in Neogene Sedimentary Rocks form the Al-Subbiyah Area, Kuwait. 13th Regional European Meeting of Sedimentology (IAS), Copenhagen, 24-26 August 1996, (Poster).

[8] Arisha, H. (1984) Stratigraphic Column of Kuwait. Unpublished Report, Ministry of Oil, Kuwait. 
[9] Fuchs, W.T., Gattinger, T.E. and Holzer, H.F. (1968) Explanatory Text to the Synoptic-Geologic Map of Kuwait: A Surface Geology of Kuwait and the Neutral Zone. Geological Survey of Austria, Vienna, 87 p.

[10] Owen, R.M.S. and Nasr, S.N. (1958) Stratigraphy of Kuwait-Basra Area. In: Habitat of Oil, Vol. 1, American Association of Petroleum Geologists, Tulsa, 1252-1278.

[11] Mazzini, A., Jonk, R., Duranti, D., Parnell, J., Cronin, B. and Hurst, A. (2003) Fluid Escape from Reservoirs: Implications from Cold Seeps, Fractures and Injected Sands. Part I. The Fluid Flow System. Journal of Geochemical Exploration, 78-79, 293-296. https://doi.org/10.1016/S0375-6742(03)00046-3

[12] Hurst, A., Scott, A. and Vigorito, M. (2011) Physical Characteristics of Sand Injectites. Earth-Science Reviews, 106, 215-246.

https://doi.org/10.1016/j.earscirev.2011.02.004

[13] Jonk, R., Mazzini, A., Duranti, D., Parnell, J., Cronin, B. and Hurst, A. (2003) Fluid Escape from Reservoirs: Implications from Cold Seeps, Fractures and Injected Sands. Part II. The Fluids Involved. Journal of Geochemical Exploration, 78-79, 297-300. https://doi.org/10.1016/S0375-6742(03)00048-7

[14] Wang, J., Zhang, Y., Liu, J. and Zhang, B. (2010) Numerical Simulation of Geofluid Focusing and Penetration Due to Hydraulic Fracture. Journal of Geochemical EXploration, 106, 211-218. https://doi.org/10.1016/j.gexplo.2009.11.009

[15] Fagereng, A., Diener, J., Meneghini, F., Harris, C. and Kvadshiem, A. (2017) Quartz Vein Formation by Local Dehydration Embrittlement along the Deep, Tremorgenic Subduction Thrust Interface. Geology, 47, 67-70. https://doi.org/10.1130/G39649.1

[16] Alehossein, H. (2009) Viscous, Cohesive, Non-Newtonian, Depositing, Radial Slurry Flow. International Journal of Mineral Processing, 93, 11-19. https://doi.org/10.1016/j.minpro.2009.04.006

[17] Balakin, B., Hoffmann, A., Kosinki, P. and Hoiland, S. (2010) Turbulent Flow of Hydrates in a Pipeline of Complex Configuration. Chemical Engineering Science, 65, 5007-5017. https://doi.org/10.1016/j.ces.2010.06.005

[18] Eskin, D. (2008) Modeling Non-Newtonian Slurry Conviction in a Vertical Fracture. Chemical Engineering Science, 64, 1591-1599.

https://doi.org/10.1016/j.ces.2008.12.019

[19] Nasr-El-Din, H., Shook, C. and Colwell, J. (1987) The Lateral Variation of Solid Concentration in Horizontal Slurry Pipeline Flow. International Journal of Multiphase Flow, 13, 661-670. https://doi.org/10.1016/0301-9322(87)90043-7

[20] Frimpong, S.S., Changirwa, R., Asa, E. and Szymanski, J. (2010) Mechanics of Oil Sand Slurry Flow in a Flexible Pipeline System. International Journal of Surface Mining, Reclamation and Environment, 16, 105-121. https://doi.org/10.1076/ijsm.16.2.105.3401

[21] Huang, C., Minev, P., Luo, J. and Nandakumar, K. (2010) A Phenomenological Model for Erosion of Material in a Horizontal Slurry Pipeline Flow. Wear, 269, 190-196. https://doi.org/10.1016/j.wear.2010.03.002

[22] Muroyama, K., Shimomichi, T., Masuda, T. and Kato, T. (2007) Heat and Mass Transfer Characteristics in a Gas-Slurry-Solid Fluidized Bed. Chemical Engineering Science, 62, 7406-7413. https://doi.org/10.1016/j.ces.2007.08.007

[23] Shook, C.A. and Roco, M.C. (1991) Slurry Flow: Principles and Practice. 2nd Edition, Butterworth-Heinemann, Stoneham, $324 \mathrm{p}$.

[24] Wilson, K.C., Sanders, R.S, Gillies, R.G. and Shook, C.A. (2010) Verification of the Near-Wall Model of Slurry Flow. Powder Technology, 197, 247-253. 
https://doi.org/10.1016/j.powtec.2009.09.023

[25] Zhou, L. (2010) Advances in Studies on Turbulent Dispersed Multiphase Flows. Chinese Journal of Chemical Engineering, 18, 889-898.

https://doi.org/10.1016/S1004-9541(09)60144-0

[26] Armanini, A., Fraccarollo, L. and Larcher, M. (2008) Liquid-Granular Channel Flow Dynamics. Powder Technology, 182, 218-227. https://doi.org/10.1016/j.powtec.2007.08.012

[27] Eskin, D., Ratulowski, J. and Akbarzadeh, K. (2011) Modeling of Particle Deposition in a Vertical Turbulent Pipe Flow at a Reduced Probability of Particle Sticking to the Wall. Chemical Engineering Science, 66, 4561-4572.

https://doi.org/10.1016/j.ces.2011.06.015

[28] Vigorito, M., Hurst, A., Cartwright, J. and Scott, A. (2008) Regional-Scale Subsurface Sand Remobilization: Geometry and Architecture. Journal of the Geological Society, 165, 609-612. https://doi.org/10.1144/0016-76492007-096

[29] Gao, H., Guo, L. and Zhang, X. (2002) Liquid-Solid Separation Phenomena of Two-Phase Turbulent Flow in Curved Pipes. International Journal of Heat and Mass Transfer, 45, 4995-5005. https://doi.org/10.1016/S0017-9310(02)00207-7

[30] Duane, M.J., Reinink-Smith, L., Eastoe, C. and Al-Mishwat, A. (2015) Mud Volcanoes and Evaporite Seismites in a Tidal Flat of Northern Kuwait-Implications for Fluid Flow in Sabkhas of the Persian (Arabian) Gulf. Geo-Marine Letters, 35, 237-246. https://doi.org/10.1007/s00367-015-0403-9

[31] Benjamin, U., Huuse, M. and Hodgetts, D. (2015) Canyon-Confined Pockmarks on the Western Niger Delta Slope. Journal of African Earth Sciences, 107, 15-27. https://doi.org/10.1016/j.jafrearsci.2015.03.019

[32] Rubin, D.M., Fairen, A., Martinez-Frais , J., Frydenvang, J., Gasnault, O., Gelfenbaum, G., Goetz, W, Grotzinger, J.P., Le Mouelic, S., Mangold, N., Newsom, H., Oehler, D.Z., Rapin, W., Schieber, J. and Wiens, R.C. (2017) Fluidized-Sediment Pipes in Gale Crater, Mars, and Possible Earth Analogs. Geology, 45, 7-10. https://doi.org/10.1130/G38339.1 